\title{
PENGARUH IMPLEMENTASI ASESMEN KINERJA TERHADAP KARAKTER DAN LITERASI SAINS SISWA KELAS IV MIN 2 KONAWE SELATAN
}

\author{
Nurzil Amri \\ Program Studi Pendidikan Guru Sekolah Dasar \\ Universitas Muslim Buton \\ Sulawesi Tenggara, Indonesia \\ e-mail: Nurzil260495@gmail.com
}

\begin{abstract}
Abstrak
Penelitian ini bertujuan untuk mengetahui apakah terdapat perbedaan implementasi asesmen kinerja terhadap karakter dan literasi sains siswa. Populasi penelitian ini berjumlah 170 siswa dan sampel berjumlah 78 siswa. Penetapan sampel dilakukan dengan teknik random sampling. Penelitian ini merupakan quasi eksperimen dengan rancangan eksperimen Single Factor Independent Group Design. Teknik pengumpulan data menggunakan kuesioner untuk karakter dan pengumpulan data literasi sains menggunakan tes objektif. Data dianalisis menggunakan multi analisis varians. Hasil penelitian menunjukkan, (1) nilai $\mathrm{F}=13,419$., p 0,001 < 0,05 yang artinya terdapat perbedaan karakter siswa yang mengikuti pembelajaran asesmen kinerja dan siswa yang mengikuti pembelajaran konvensional dengan pendekatan saintifik. (2) nilai $F=15,797$., $p$ $0,001<0,05$ yang artinya terdapat perbedaan literasi sains siswa yang mengikuti pembelajaran asesmen kinerja dan siswa yang mengikuti pembelajaran konvensional dengan pendekatan saintifik. (3) nilai $\mathrm{F}=14,182$., $\mathrm{p} 0,001<$ 0,05 yang artinya terdapat perbedaan karakter dan literasi sains secara simultan antara siswa yang mengikuti pembelajaran asesmen kinerja dengan siswa yang mengikuti pembelajaran konvensional dengan pendekatan saintifik. Dapat disimpulkan bahwa terdapat perbedaan karakter dan literasi sains siswa yang mengikuti pembelajaran saintifik menggunakan asesmen kinerja dan siswa yang mengikuti pembelajaran saintifik menggunakan konvensional di kelas IV MIN 2 Konawe Selatan.
\end{abstract}

\begin{abstract}
This study aims to determine whether there are differences in the implementation of performance assessments on students' character and scientific literacy. The population of this research is 170 students and the sample is 78 students. The sample was determined by using random sampling technique. This study is a quasiexperimental study with a Single Factor Independent Group Design experimental design. The data collection technique used a questionnaire for character and scientific literacy data collection used an objective test. Data were analyzed using multi analysis of variance. The results showed, (1) the value of $\mathrm{F}=13.419$., $\mathrm{P} 0.001<0.05$, which means that there are differences in the student's character who took the performance assessment learning and students who took conventional learning with a scientific approach. (2) the value of $\mathrm{F}=15.797$., $\mathrm{P} 0.001<0.05$, means that there are differences in the students' scientific literacy of who took performance assessment learning and students who took conventional learning with a scientific approach. (3) the value of $\mathrm{F}=14,182$., $\mathrm{P} 0.001$ $<0.05$, means that there are differences in character and scientific literacy simultaneously between students who took performance assessment learning and students who took conventional learning with a scientific approach. It can be concluded that there are differences in character and students' scientific literacy who took scientific learning using performance assessments and students who took conventional scientific learning in class IV MIN 2 South Konawe.
\end{abstract}

Keywords: Performance Assessment, Character, Science Literacy

\section{PENDAHULUAN}

Pendidikan merupakan sarana pembekalan ilmu pengetahuan, keterampilan, nilai dan moral melalui kegiatan pembelajaran dan kegiatan lainnya yang terhubung dengan rencana pendidikan di suatu lembaga sekolah. Dalam Undang-undang Sistem Pendidikan Nasional 
Nomor 20 Tahun 2003 Pasal 1 dijelaskan bahwa, Pendidikan adalah usaha sadar dan terencana untuk mewujudkan suasana belajar dan proses pembelajaran agar peserta didik secara aktif mengembangkan potensi dirinya untuk memiliki kekuatan spiritual keagamaan, pengendalian diri, kepribadian, kecerdasan, akhlak mulia, serta keterampilan yang diperlukan dirinya, masyarakat, bangsa dan negara (Hendriana dan Arnold Jacobus, 2016). Dari rumusan ini terlihat bahwa pendidikan nasional mengemban misi yang tidak ringan, yakni membangun manusia yang utuh dan paripurna yang memiliki nilai-nilai karakter yang agung di samping juga harus memiliki keimanan dan ketakwaan. Karena itulah pendidikan menjadi agent of change yang harus mampu melakukan perbaikan karakter bangsa. Dengan demikian, pendidikan karakter merupakan upaya dasar dan sistematis baik oleh sekolah maupun pemerintah untuk membantu siswa menggembangkan nilai-nilai pokok (core vaule), nilai-nilai etik dan nilai-nilai kinerja, seperti kepedulian, kejujuran, kerajinan, fairness, keuletan dan ketabahan (fortitude) (Suastra, 2018).

Namun, pengaruh negatif kemajuan zaman sekarang ini tampaknya cukup signifikan di seantero dunia, termasuk di Indonesia. Suastra (2018) saat ini berbagai persoalan dialami bangsa Indonesia, seperti maraknya intoleransi, radikalisme, terorisme, saling curiga mencurigai, fitnah di media sosial (Hoak), korupsi, pemerasan/kekerasan (bullying), kekerasan/dominasi senior oleh yunior bahkan sampai memakan korban meninggal dunia, penggunaan narkoba (BNN menyatakan ada lebih dari 3,6 juta penduduk pecandu narkoba di Indonesia tahun 2010), ucapan/ujaran kebencian, rapuhnya rasa kebangsaan baik dari kalangan masyarakat biasa sampai perguruan tinggi, serta adanya sekelompok masyarakat yang ingin mengganti dasar negara kita Pancasila yang berlandaskan kebhinekaan dengan ideologi lain. Hal senada dikemukakan oleh Komnas HAM yang mencatan 4 kondisi darurat pendidikan Indonesia, yaitu: 1) darurat karena banyak kasus pelanggaran HAM, hal ini sebagaimana ungkapat (UNICEF) data badan persatuan bangasa-bangasa untuk anak, 1 dari 3 anak perempuan dan 1 dari 4 anak laki-laki Indonesia mengalami kekerasan. Berdasarkan data dari Komnas HAM, kasus dugaan pelanggaran HAM terkait isu pendidikan cenderung meningkat. Pada 2017 terdapat 19 kasus, sedangkan awal 2018 sampai April 2018 sudah ada 11 kasus. Tempat kejadiannya ada di Sumatera, Jawa, Sulawesi, Kalimantan, Maluku, Papua, Bali dan Nusa Tenggara, 2) Darurat kerena ranking pendidikan Indonesia buruk, 3) kondisi yang terjadi lantaran banyak kasus korupsi yang berkaitan dengan anggaran pendidikan, 4) sistem pendidikan belum berjalan dengan baik (Nadlir, 2018).

Disamping karakter yang sangat penting, di era abad 21 sangat penting pula mengenai literasi. Menurut PISA (Programme of International Student Assessment), salah satu literasi yang sangat penting adalah literasi sains. Yuriza dkk (2018) mengatakan bahwa literasi sains sangat penting dimiliki oleh siswa. Siswa yang memiliki literasi sains akan dapat menerapkan pengetahuan mereka untuk memecahkan permasalahan dalam situasi kehidupan sehari-hari baik dalam lingkup pribadi, sosial atau pun global. Menurut Imaningtyas dkk (2016) untuk meningkatkan literasi sains dalam pembelajaran sains yaitu dengan menghubungkan suatu konsep sains dengan topik yang sedang berkembang dan menarik dalam kehidupan nyata. Peserta didik diharapkan menjadi aktif dalam pembelajaran dengan menggunakan topik yang baru dan menarik dalam kehidupan nyata. NRC (National Science Standards) dalam Toharudin dalam Asyhari (2015) menyatakan bahwa, literasi sains merupakan kemampuan untuk menggunakan pengetahuan sains dalam upaya memecahkan masalah. Literasi sains penting untuk dikuasai oleh peserta didik dalam kaitannya dengan cara peserta didik itu dapat memahami lingkungan hidup, kesehatan, ekonomi, dan masalah-masalah lain yang dihadapi oleh masyarakat modern yang sangat bergantung pada teknologi dan kemajuan, serta perkembangan ilmu pengetahuan. Namun kenyataannya, saat ini literasi sains di Indonesia cukup memprihatinkan. Hal ini dapat dilihap dari hasil PISA pada tahun 2015 yang menunjukkan rata-rata literasi sains siswa sebesar 403 dengan rata-rata sebesar 501 dan berada 
pada peringkat 62 dari 72 negara peserta. Sementara tahun 2012 hasil survei PISA menunjukkan rata-rata literasi sains siswa Indonesia sebesar 382 dengan rata-rata sebesar 501 dan berada pada rangking 59 dari 64 negara peserta. Tingkat rendahnya disebabkan oleh pemahaman tentang pembelajaran sains yang mengarahkan siswa pada pembentukan literasi sains yang tidak lengkap dari siswa yang dipahami oleh para guru. Dalam aspek konten, hal ini disebabkan oleh proses pembelajaran sains yang masih fokus pada menghafal, sehingga siswa tidak mengerti apa yang mereka pelajari tetapi hanya menghafal (Jufri dalam Fakhriyah dkk, 2017).

Berdasarkan kajian diatas, untuk memperbaiki karakter dan literasi sains peserta didik dapat dilakukan dengan menerapkan asesmen autentik dalam pembelajaran. Asesmen adalah poses pengumpulan informasi tentang siswa, yakni apa yang mereka ketahui dan apa yang mereka dapat kerjakan (Hart dalam Suastra, 2017). Asesmen autentik (authentic assesment) adalah suatu proses pengumpulan, pelaporan dan penggunaan informasi tentang hasil belajar siswa dengan menerapkan prinsip-prinsip penilaian, pelaksanaan berkelanjutan, bukti-bukti autentik, akurat, dan konsisten sebagai akuntabilitas publik (Alfian dkk, 2015). Salah satu jenis asesmen autentik di SD dalam kurikulum 2013 adalah asesmen kinerja. Marhaeni, dkk (2017) asesmen kinerja (Performance Assessment) adalah suatu prosedur yang menggunakan berbagai bentuk tugas-tugas untuk memperoleh informasi tentang apa dan sejauh mana yang telah dilakukan dalam suatu program. Pemantauan didasarkan pada kinerja (Performance) yang ditunjukkan dalam menyelesaikan suatu tugas atau permasalahan yang diberikan. Paige (2005) mengemukakan bahwa penilaian kinerja merupakan proses yang terdiri atas mendefinisikan, memilih, mendesain, mengumpulkan, menganalisis, menginterpretasi, dan menggunakan informasi.

Serevina dan Mulyati (2018), Penilaian kinerja adalah penilaian dalam bentuk demonstrasi yang digunakan untuk menentukan penilaian siswa keterampilan atau keterampilan tentang sesuatu, seperti menunjukkan gerakan, dan sebagainya. Penilaian kinerja adalah bagian dari penilaian otentik yang dianggap mampu untuk lebih mengukur hasil belajar siswa secara keseluruhan, karena penilaian ini mengevaluasi kemajuan belajar tidak melalui hasil tetapi juga proses dan dengan berbagai cara. Hibbard dalam Suastra (2017) menyebutkan alasan penggunaan asesmen kinerja dalam pembelajaran sains, 1) memperkenalkan pembelajaran autentik, 2) memfasilitasi pembelajaran mandiri, 3) mengembangkan keterampilan berfikir, 4) mendorong gaya belajar yang berbeda, 5) mendayagunakan pembelajaran kooperatif, 6) memacu keikutsertaan siswa dan orang tua. Berdasarkan kajian di atas, dapat diungkapkan bahwa implementasi asesmen kinerja diduga dapat memberikan pengaruh terhadap karakter dan literasi sains siswa. Namun besarnya pengaruh tersebut belum dapat diketahui dengan pasti. Penelitian ini bertujuan untuk, 1) mengetahui perbedaan karakter siswa yang mengikuti pembelajaran asesmen kinerja dan siswa yang mengikuti pembelajaran konvensional dengan pendekatan saintifik 2) mengetahui perbedaan literasi sains pada siswa yang mengikuti pembelajaran asesmen kinerja dan siswa yang mengikuti pembelajaran konvensional dengan pendekatan saintifik, 3) mengetahui perbedaan secara simultan karakter dan literasi sains siswa yang mengikuti pembelajaran asesmen kinerja dan siswa yang mengikuti pembelajaran konvensional dengan pendekatan saintifik.

\section{METODE}

Penelitian ini merupakan penelitian eksperimen semu (quasi eksperimen) terhadap siswa dalam suatu kelas. Rancangan eksperimen yang digunakan adalah rancangan eksperimen Single Factor Independent Group Design. Rancangan Penelitian yang dilakukan dengan Single Factor Independent Group Desain (Dantes, 2017) sebagai berikut; 
Tabel 1 rancangan penelitian

(Single Factor Independent Group Desain)

\begin{tabular}{|c|c|c|c|}
\hline \multicolumn{2}{|c|}{$\begin{array}{c}\text { Eksperimen } \\
(\mathrm{E})\end{array}$} & \multicolumn{2}{c|}{$\begin{array}{c}\text { Konvensional } \\
(\mathrm{K})\end{array}$} \\
\hline $\mathrm{Y} 1$ & $\mathrm{Y} 2$ & $\mathrm{Y} 1$ & $\mathrm{Y} 2$ \\
\hline. &. &. &. \\
\hline. &. &. &. \\
\hline. &. &. &. \\
\hline
\end{tabular}

Keterangan:

$\mathrm{E} \quad=$ Kelompok Eksperimen

$\mathrm{K}=$ Kelompok Konvensional

$\mathrm{Y} 1=$ Karakter

Y2 = Literasi Sains

Penelitian ini dilaksanakan pada semester 1 tahun ajar 2019/2020. Populasi dalam penelitian ini adalah seluruh siswa kelas IV MIN 2 Konawe Selatan yang berjumlah 170 siswa. Sampel dalam penelitian ini dilakukan dengan random sampling diperoleh sampel sebanyak 78 siswa dimana di MIN 2 Konawe Selatan.

Pengumpulan data dalam penelitian ini menggunakan kuesioner untuk karakter dan tes untuk literasi sains. Uji prasyarat analisis dalam penelitian ini adalah, 1) uji normalitas sebaran data, 2) uji homogenitas, dan 3) uji korelasi antar variabel terikat. Analisis data yang digunakan adalah MANOVA.

\section{HASIL DAN PEMBAHASAN}

\section{Hasil Penelitian}

Hasil penelitian yang telah dilakukan, diperoleh data skor literasi sains dan karakter siswa sebagai berikut;

Tabel 2 Hasil Analisis Deskriptif Literasi Sains dan Karakter Siswa Antara Kelompok Kontrol dan Kelompok Eksperime

\begin{tabular}{|c|l|l|l|l|}
\hline & A1Y1 & A1Y2 & A2Y1 & A2Y2 \\
\hline $\begin{array}{c}\text { N } \\
\text { (Sampel) }\end{array}$ & 32 & 32 & 31 & 31 \\
\hline $\begin{array}{c}\text { Nilai } \\
\text { Minimum }\end{array}$ & 45 & 62,29 & 45 & 72,57 \\
\hline $\begin{array}{c}\text { Nilai } \\
\text { Maximum }\end{array}$ & 80 & 90,29 & 85 & 96,57 \\
\hline Rerata & 61,72 & 78,76 & 70,97 & 84,82 \\
\hline
\end{tabular}

Keterangan:

A1Y1 =Literasi Siswa Kelompok Kontrol

A1Y2 =Karakter Siswa Kelompok Kontrol

A2Y1 =Literasi Siswa Kelompok Eksperimen

A2Y2 =Karakter Siswa Kelompok Eksperimen

Berdasarkan data pada Tabel 2 dapat dilihat bahwa rata-rata literasi sains siswa dan karakter siswa secara keseluruhan terjadi peningkatan. Sebelum dilakukan uji hipotesis terlebih dahulu dilakukan uji normalitas, homogenitas dan korelasi pada data rata-rata literasi sains dan karakter siswa secara keseluruhan dengan bantuan SPSS 16 yang dirangkum pada Tabel 3 
Tabel 3 Hasil Uji Normalias

\begin{tabular}{|c|c|c|c|c|}
\hline \multirow{2}{*}{$\begin{array}{l}\overline{\mathbb{D}} \\
\stackrel{\vec{\Xi}}{\vec{\Xi}} \\
\stackrel{\nabla}{>}\end{array}$} & \multicolumn{3}{|c|}{$\begin{array}{l}\text { Kolmogorov- } \\
\text { Smirnov }\end{array}$} & \multirow{2}{*}{ 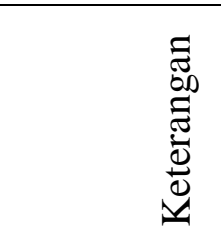 } \\
\hline & 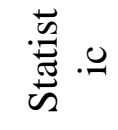 & Df & Sig. & \\
\hline A1Y1 & 0,122 & 32 & 0,200 & $\begin{array}{l}\text { Berdistribusi } \\
\text { normal }\end{array}$ \\
\hline A1Y2 & 0,073 & 32 & 0,200 & $\begin{array}{l}\text { Berdistribusi } \\
\text { normal }\end{array}$ \\
\hline A2Y1 & 0,145 & 31 & 0,095 & $\begin{array}{l}\text { Berdistribusi } \\
\text { normal }\end{array}$ \\
\hline A2Y2 & 0,112 & 31 & 0,200 & $\begin{array}{l}\text { Berdistribusi } \\
\text { normal }\end{array}$ \\
\hline
\end{tabular}

Berdasarkan Tabel 3, sebaran data literasi sains dan karakter siswa kelompok eksperimen dan kelompok kontrol "berdistribusi normal”.

Tabel 4 Hasil Uji Homogenitas

\begin{tabular}{|l|l|l|}
\hline \multicolumn{2}{|l|}{ Uji Box's $M$} & 7,427 \\
\hline \multirow{4}{*}{ F } & Approx & 2,457 \\
\cline { 2 - 3 } & df1 & 3 \\
\cline { 2 - 3 } & df2 & $2,678 \mathrm{E} 4$ \\
\cline { 2 - 3 } & Sig. & 0,061 \\
\hline
\end{tabular}

Berdasarkan Tabel 4 di atas tampak jelas bahwa angka signifikansi lebih besar dari 0,05 dan $X^{2}$ hitung $(7,427)<X^{2}$ tabel $(7,815)$. Dengan demikian, matrik varian-kovarian terhadap variabel literasi sains dan karakter siswa adalah homogeny

Tabel 5 Hasil Uji Korelasi

\begin{tabular}{|l|l|l|}
\hline $\begin{array}{l}\text { Nilai } r_{x y} \\
\text { Pearson's Correlation }\end{array}$ & Sig & Keputusan \\
\hline 0,203 & 0,110 & $\begin{array}{l}\text { Tidak } \\
\text { Signifikan }\end{array}$ \\
\hline
\end{tabular}

Tabel 5 menunjukkan bahwa $r_{x y}$ untuk Literasi Sains bernilai 0,203 dan Karakter 0,203. Hal ini menunjukkan bahwa nilai $r_{x y}<$ dari 0,8 . maka kedua variabel terikat tersebut tidak kolonier.

\section{Pembahasan}

Pengujian hipotesis pertama menggunakan analisis varian satu jalur (ANAVA A) melalui statistik varian (F antar) diperoleh nilai F sebesar 13,419 Db $=1$ dan $\mathrm{Sig}=0,001$.

Hasil temuan perbedaan pencapaian karakter tersebut dapat dijelaskan penyebabnya dari sudut pandang teoritik antara siswa yang mengikuti pembelajaran asesmen kinerja dan siswa yang mengikuti pembelajaran konvensional dengan pendekatan saintifik dimana keduanya memiliki karakteristik berbeda. Hal tersebut akan sangat berbeda pada komponen-komponen model pembelajaran konvensional terdiri dari tahap pertama kegiatan awal, dimana guru yang menentukan masalah dalam pembelajaran, tahap kedua kegiatan inti, dimana guru menyampaikan materi pembelajaran dengan uraian-uraian dan mengontrol pemahaman siswa dengan beberapa pertanyaan dan tugas-tugas, tahap ketiga penutu dimana guru bertugas untuk 
menyimpulkan pelajaran agar setiap anak lebih memahami materi yang disampaikan dan melakukan evaluasi. Oleh karena itu, pada prinsipnya pembelajaran yang dapat mengaktifkan siswa akan berdampak yang positif terhadap hasil belajar. Disamping itu, pembelajaran aktif juga dimaksudkan untuk menjaga perhatian siswa agar tetap tertuju pada proses pembelajaran. Karakteristik asesmen kinerja yaitu, melakukan, membuat, atau menghasilkan sesuatu; mengetuk keterampilan berpikir tingkat tinggi dan memecahkan masalah; menggunakan tugas yang mewakili kegiatan pembelajaran yang berarti; melibatkan aplikasi dunia nyata; dan menggunakan penilaian manusia dalam penilaian (Bland, 2018). Karakteristik pembelajaran konvensional yaitu, menggunakan kelas sebagai satu-satunya tempat belajar, mengajar lebih banyak menggunakan metode ceramah, memberikan kegiatan yang tidak bervariasi, berkomunikasi dengan satu arah, mengajar hanya menggunakan buku sebagai belajar dan informasi dari guru, hanya menilai hasil belajar (Wasno, 2009). Penelitian lain yang senada dengan penelitian ini dilakukan oleh Sofli dan Ajat Sudrajat (2014) dengan judul Peningkatan Karakter Siswa Melalui Pembelajaran IPS Terpadu Model Nested Di SMP Negeri 3 Banguntapan Bantul. Dalam hasil penelitian tersebut menunjukkan bahwa ada peningkatan karakter peserta didik berdasarkan hasil observasi di kelas VII G SMP N 3 Banguntapan, Bantul tahun pembelajaran 2013/2014. Pengujian hipotesis kedua menggunakan analisis varian satu jalur (ANAVA A) melalui statistik varian ( $\mathrm{F}$ antar) diperoleh nilai $\mathrm{F}$ sebesar $15,797 \mathrm{Db}=1$ dan Sig $=0,001$.

Dengan kata lain, bahwa implementasi asesmen kinera dalam pembelajaran lebih unggul dibandingkan dengan pembelajaran yang tidak menggunakan asesmen kinerja, hal ini dilihat dari hasil pencapaian literasi sains. Asesmen kinerja adalah suatu prosedur yang menggunakan berbagai bentuk tugas-tugas untuk memperoleh informasi tentang apa dan sejauh mana yang telah dilakukan dalam suatu program. Asesmen kinerja dikatakan sebagai sebuah asesmen autentik karena dalam asesmen kinerja, peserta didik diharapkan untuk mendemonstrasikan inkuiri ilmiah mereka, serta melakukan penalaran dan keterampilan dalam menyelesaikan beberapa tugas menarik dan menantang dalam konteks kehidupan nyata (Marhaeni, dkk. 2017). Penilaian berbasis kinerja mewakili seperangkat strategi untuk penerapan pengetahuan, keterampilan, dan kebiasaan kerja melalui kinerja tugas yang bermakna dan menarik bagi siswa (Hibbard dkk, 1996). Jenis penilaian ini memberi para guru informasi tentang bagaimana seorang anak memahami dan menerapkan pengetahuan. Selain itu, guru dapat mengintegrasikan penilaian berbasis kinerja kedalam proses pembelajaran untuk memberikan pengalaman belajar tambahan bagi siswa (Brualdi, 1998).

Sebuah studi tentang Penilaian Kinerja yang dilakukan oleh Universitas Marmara pada tahun 2008 di Jakarta menunjukkan bahwa penilaian kinerja ini memberikan bantuan kepada siswa untuk membangun dan mengembangkan ilmunya, dimana pengajaran dan penilaian adalah dua proses yang saling memberi makna. Oleh karena itu, penilaian kinerja dianggap sangat diperlukan sebagai perantara yang mampu memberikan umpan balik kepada siswa dalam proses pembelajaran, (Serevina dan Muliyati, 2018).

Pengujian hipotesis ketiga dilakukan dengan uji $\mathrm{F}$ melalui MANOVA melalui Pillai's Trace, Wilks' Lambda, Hotelling's Trace dan Roy's Largest Root diperoleh nilai Fhitung 14,182 dengan taraf signifikan 0,01, artinya nilai ini lebih kecil dari 0,05 (sig. < 0,05). Jadi hopotesis nol yang menyatakan tidak terdapat perbedaan karakter dan literasi sains siswa secara simultan yang mengikuti pembelajaran saintifik menggunakan asesmen kinerja dan siswa yang mengikuti pembelajaran saintifik menggunakan asesmen konvensional ditolak dan hipotesis alternatif diterima. Dengan demikian terdapat perbedaan karakter dan literasi sains siswa secara simultan yang mengikuti pembelajaran saintifik menggunakan asesmen kinerja dan siswa yang mengikuti pembelajaran saintifik menggunakan asesmen konvensional pada kelas IV MIN 2 Konawe Selatan. 
Berdasarkan hasil penelitian menunjukkan bahwa terdapat hubungan positif antara literasi sains dengan karakter siswa denga kekuatan korelasi sebesar 0,203. Dalam hal tersebut bisa kita lihat bahwa adanya hubungan langsung antara literasi sains dan karakter. Artinya bahwa semakin tinggi kemampuan literasi sains siswa, maka akan semakin baik pula karakter siswa. Dalam hal ini juga proses pembelajaran harus dipersiapkan dengan matang sehingga akan lebih efektif dan efisien yang tentunya akan berpengaruh pada literasi sains dan karakter siswa. Pendidik juga memiliki peranan penting untuk menfasilitasi, membimbing dan membangkitkan kemampuan literasi dan keaktifan siswa dalam kelas. Penilaiann asesmen kinerja mampu memenuhi apa yang dibutuhkan siswa selama pendidik selalu berupaya untuk merancang pembelajaran yang bermakna agar dapat meningkatkan kemampuan literasi sains dan karakter siswa.

Hasil penelitian ini sejalan dengan yang dilakukan oleh Nilalohita (2017) denga judul Budaya Literasi Dalam Pembentukan Karakter. Hasil penelitian menyatakan terdapat hubungan positif antara kemapuan literasi secara simultan dengan kemampuan karakter pada siswa.

\section{KESIMPULAN}

Berdasarkan hasil penelitian yang telah dilakukan dapat disimpulkan: Pengujian hipotesis pertama menggunakan analisis varian satu jalur (ANAVA A) melalui statistik varian (F antar) diperoleh nilai $\mathrm{F}$ sebesar $13,419 \mathrm{Db}=1$ dan $\mathrm{Sig}=0,001$. Terdapat perbedaan karakter siswa yang mengikuti pembelajaran saintifik menggunakan asesmen kinerja dan siswa yang mengikuti pembelajaran saintifik menggunakan asesmen konvensional. Pengujian hipotesis kedua menggunakan analisis varian satu jalur (ANAVA A) melalui statistik varian (F antar) diperoleh nilai $\mathrm{F}$ sebesar $15,797 \mathrm{Db}=1$ dan $\mathrm{Sig}=0,001$. Terdapat perbedaan literasi sains siswa yang mengikuti pembelajaran saintifik menggunakan asesmen kinerja dan siswa yang mengikuti pembelajaran saintifik menggunakan asesmen konvensional. Pengujian hipotesis ketiga dilakukan dengan uji F melalui MANOVA melalui Pillai's Trace, Wilks' Lambda, Hotelling's Trace dan Roy's Largest Root diperoleh nilai Fhitung 14,182 dengan taraf signifikan 0,01 , artinya nilai ini lebih kecil dari 0,05 ( sig. < 0,05). Terdapat perbedaan secara simultan karakter dan literasi sains siswa yang mengikuti pembelajaran saintifik menggunakan asesmen kinerja dan siswa yang mengikuti pembelajaran saintifik menggunakan asesmen konvensional.

Hal ini menunjukkan bahwa implementasi asesmen kinerja dapat dijadikan sebagai acuan bagi pengembang penelitian berikutnya. Dengan demikian, hasil penelitian ini disarankan dapat dijadikan sebagai kajian empiris melalui pengembangan penelitian lanjut mengenai asesmen kinerja secara lebih luas dan mendalam.

\section{DAFTAR PUSTAKA}

Alfian, dkk. 2015. Authentic Assessment Berbasis Scientific Approach sebagai Implementasi Kurikulum 2013 Di SMP Kelas VII pada Materi Suhu dan Perubahannya. Jurnal Inkuiri. Volume 4, Nomor 3.

Asyhari, A. dan Risa Hartati. 2015. Profil Peningkatan Kemampuan Literasi Sains Siswa Melalui Pembelajaran Saintifik. Jurnal Ilmiah Pendidikan Fisika Al-Biruni. 04 (2). Doi: 10.24042

Bland., et.al. 2018. Performance Assessments: A Review of Definitions, Quality Characteristics, and Outcomes Associated with Their Use in K-12. Schools Teacher Educators' Journal. V11 p52-69 
Brualdy, A. 1998. Implementing Performance Assessment in the Classroom. ERIC Clearing house on Assessment and Evaluation.

Dantes, N. 2017. Desain Eksperimen dan Analisis Data. Depok: PT Raja Grasindo Persada.

Fakhriyah, F., dkk. 2017. Student's Science Literacy In The Aspect Of Content Science? Jurnal Pendidikan IPA Indonesia. DOI: 10.15294/jpii.v6i1.7245

Hendriana, E.C. dan Arnold Jacobus. 2016. Implementasi Pendidikan Karakter Di Sekolah Melalui Keteladanan dan Pembiasaan. Jurnal Pendidikan Dasar Indonesia. Volum 1 Nomor 2

Imaningtyas, C.D., et.al. 2016. Penerapan E-Module Berbasis Problem Based Learning Untuk Meningkatkan Literasi Sains dan Mengurangi Miskonsepsi Pada Materi Ekologi Siswa Kelas X MIA 6 SMAN 1 Karanganom Tahun Pelajaran 2014/2015. BIOEDUKASI. Volume 9, Nomor 1

Marhaeni, A.A.I.N., dkk. 2017. Asesmen Autentik Dalam Pembelajaran Bahasa Inggris. Depok: PT Raja Grafindo Persada

Nilalohota, C.S. 2017. Budaya Literasi dalam Pembentukan Karakter Siswa. Jakarta: UIN Syarif Hidayatullah Jakarta.

Nadlir, Moh. 2018. KOMNAS HAM Catat 4 Kondisi Darurat Pendidikan Indonesia. https://nasional.kompas.com/read/2018/05/02/12581141/komnas-ham-catat-4-kondisidarurat-pendidikan-indonesia. Diakse pada tanggal 23 Agustus 2018.

Paige, R. M. (2005). Internatioalization of higher education: performance assessment and indicator. University of Minnesota, College of Education and Human Development.

Serevina, V and Muliyati, D. 2018. Development of student performance assessment based on scientific approach for a basic physics practicum in simple harmonic motion materials. Journal of Physics: Conference Series

Suastra, I.W. 2017. Asesmen Dalam Pembelajaran Sains. Singaraja: Universitas Pendidikan Ganesha.

Suastra, I.W. 2017. Pembelajaran Sains Terkini Mendekatkan Siswa Dengan Lingkungan Alamiah dan Sosial Budayanya. Singaraja: Universitas Pendidikan Ganesha

Suastra, I.W. 2018. Peran Guru Dalam Pengembangan Karakter Siswa Untuk Menjaga Keutuhan dan Kemajuan Bangsa Indonesia. Jurnal Pendidikan, Agama dan Budaya. Volume 1, Nomor 1

Sofli dan Ajat Sudrajat. 2014. Peningkatan Karakter Siswa Melalui Pembelajaran IPS Terpadu Model Nested di SMP Negeri 3 Banguntapan Bantul. Jurnal Harmoni Sosial, Volume 1 Nomor 1 
Yuriza, P.E., dkk. 2018. Hubungan Antara Kemampuan Berpikir Tingkat Tinggi dan Tingkat Kecerdasan dengan Kemampuan Literasi Sains Pada Siswa SMP. Jurnal Pendidikan Biologi (biosferjpb). Tahun 2018, Volume 11 No 1

${ }^{*}$ Corresponding author.

E-mail Addresses: Nurzil260495@gmail.com (Nurzil Amri) 